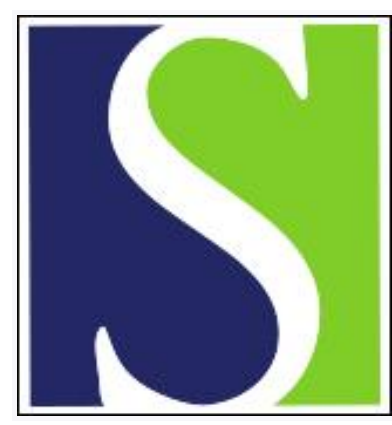

Scand J Work Environ Health 1995;21(1):43-50

https://doi.org/10.5271/sjweh.7

Issue date: Feb 1995

Assessment and grouping of occupational magnetic field exposure in five electric utility companies

by Kromhout H, Loomis DP, Mihlan GJ, Peipins LA, Kleckner RC, Iriye R, Savitz DA

The following article refers to this text: 2018;44(1):80-87

Key terms: exposure assessment; exposure level; magnetic field; misclassification; occupational exposure; precision; resolution

This article in PubMed: www.ncbi.nlm.nih.gov/pubmed/7784864

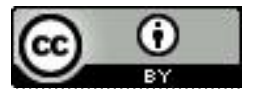




\title{
Assessment and grouping of occupational magnetic field exposure in five electric utility companies
}

\author{
by Hans Kromhout, PhD, 1,2 Dana P Loomis, PhD, ${ }^{2}$ Gary J Mihlan, MSc, ${ }^{3}$ Lucy A Peipins, PhD, ${ }^{4}$ \\ Robert C Kleckner, PhD, ${ }^{2}$ Richard Iriye, BS, ${ }^{5}$ David A Savitz, PhD ${ }^{2}$
}

\begin{abstract}
Kromhout H, Loomis DP, Mihlan GJ, Peipins LA, Kleckner RC, Iriye R, Savitz DA. Assessment and grouping of occupational magnetic field exposure in five electric utility companies Scand J Work Environ Health 1995; $21: 43-50$

Objectives Occupational exposure to $60-\mathrm{Hz}$ magnetic fields was surveyed among randomly selected workers in five electric power companies.

Methods The study facilitated the examination of exposure variability and provided the base for a jobexposure matrix linking health outcomes and occupational magnetic field exposures.

Results Average exposures ranged from 0.11 to $1.50 \mu \mathrm{T}$. The differences among the five companies were small, the more urban companies showing somewhat higher averages. The day-to-day component of variance exceeded the within- and between-group components of variance. The final job-exposure matrix consisted of five groups with average exposure levels of $0.12,0.21,0.39,0.62$, and $1.27 \mu \mathrm{T}$. Given the variance in exposure, even this optimal grouping considerably overlapped.

Conclusions The job-exposure matrix used in this study efficiently incorporated the differences in exposure within occupational categories between companies and provided an objective and statistically based method for estimating cumulative magnetic field exposure.
\end{abstract}

Key terms exposure assessment, magnetic field exposure levels, misclassification, occupational exposure, precision, resolution.

Concern about occupational exposure to $50-$ and $60-\mathrm{Hz}$ power-frequency electric and magnetic fields has intensified since epidemiologic surveys a decade ago suggested excess cancer mortality among workers in electrical occupations ( $1-4)$. Although further studies of health risks among electrical workers have been conducted (5), quantitative data concerning the level of occupational exposure to power-frequency electromagnetic fields remain relatively sparse and of limited quality (6).

In one earlier study, Deadman et al (7) assessed $60-\mathrm{Hz}$ electric and magnetic field exposures over $7 \mathrm{~d}$ among 36 electric utility workers in Canada and provided information on both occupational and nonwork exposures. Flynn et al (8) presented data describing workshift magnetic field exposures from a similar survey of
134 electric utility workers in the United States. Bowman et al (9) obtained 141 area spot measurements of occupational electric and magnetic field exposures among workers in selected electrical occupations and a sample of other jobs in the Los Angeles area.

These studies indicated high exposures to electric or magnetic fields but had important limitations in that few workers were monitored in each job, subjects were not randomly selected, and, in the Los Angeles study, only short-term measurements were taken. Other exposure assessments were performed in conjunction with epidemiologic studies, but only limited information concerning exposure has been published $(10-11)$. Additional occupational exposure studies have been conducted, including a very large one among electric utility volunteers, but

1 Department of Air Quality, Wageningen Agricultural University, Wageningen, The Netherlands.

2 Department of Epidemiology, School of Public Health, University of North Carolina, Chapel Hill, North Carolina, United States.

3 Department of Environmental Sciences and Engineering, School of Public Health, University of North Carolina, Chapel Hill, North Carolina, United States.

4 National Institute for Occupational Safety and Health, Cincinnati, Ohio, United States.

5 Enertech Consultants, Campbell, California, United States.

Reprint requests to: Dr Hans Kromhout, Department of Air Quality, Wageningen Agricultural University, PO Box 8129, 6700 EV Wageningen, The Netherlands. 
the results have not yet appeared in widely available, refereed publications (12-13).

Previous assessments of occupational exposure to power frequency electromagnetic fields have particular deficiencies with regard to two key methodological points. Variability between workers and over time is increasingly recognized as an aspect of occupational exposure with importance for both research and regulation (14-16). Some data concerning exposure variability are available from two studies of exposures in electric utilities $(7,12,17)$, but they may be compromised by nonrandom selection of subjects and the use of consecutive measurement days. This issue has not been thoroughly considered in other assessments of occupational electric and magnetic field exposure. The need to reduce exposure misclassification through the appropriate grouping of workers for epidemiologic analysis has also been recognized as an important determinant of validity, but objective techniques for doing so have not been addressed in any previous study of occupational electric and magnetic field exposure.

We conducted a large survey of occupational exposure to $60-\mathrm{Hz}$ magnetic fields among randomly selected workers in 28 job categories in five electric utility companies (18-20). In relation to earlier assessments of occupational magnetic field exposure, this study has several design advantages that facilitate the examination of exposure variability. They include large sample size, random selection of workers and measurement days, and the use of full-shift personal monitoring. In the present report we present the results of the survey describing magnetic field exposures among electric utility workers. In addition, we analyze aspects of exposure variability within and between occupational groups and workers and present a statistically optimal job-exposure matrix for linking health outcomes and occupational magnetic field exposures in the epidemiologic study of the employees of these companies.

\section{Materials and methods}

Details of the sampling design and field methods of the magnetic field exposure survey have been described elsewhere (18), as have the classification and organization of the work history data from the cohort (19). A brief description of the survey is provided.

\section{Sampling design}

Initially, occupational categories were constructed to organize thousands of job titles at five electric utility companies participating in a cohort mortality study into logical and homogeneous groups. Using experience gained from two preliminary surveys, the 28 occupational categories were then aggregated into three ordinal levels of presumed magnetic field exposure (table 1). A goal of 4000 full-shift magnetic field measurements was set, based principally on considerations of time, cost, and the tolerance of the participating companies. The number of measurements to be made in each occupational category was a function of the total number of measurements projected, arbitrary weights of one, three, or five for the three exposure levels, and a second set of weights proportional to person-years of employed experience contributed by each of the five companies. The rationale for the weights of one, three, and five was that groups with higher average exposures would also have more variable exposures, requiring more measurements to obtain equally precise estimates of average exposures.

To enable the estimation of within- and betweenworker components of exposure variance, each individual selected for monitoring in the "medium" and "high" exposure groups was measured on two randomly selected days no more than 12 months apart. The temporal variability in exposure in the "low" exposure group was expected to be small; therefore study resources were conserved by measuring workers in these occupational categories only once.

\section{Instrumentation}

A small, integrating, personal magnetic-field-exposure meter (the AMEX 3-D) (21) was used to measure magnetic field exposure. This meter yields an estimate of cumulative magnetic field exposure which can be translated to a time-weighted average (TWA). The AMEX 3-D does not provide time-specific magnetic field data and does not measure electric fields in contrast to the EMDEX-100 (12) and the IREQ dosimeter used by Deadman et al $(7,22)$.

\section{Survey protocol and data handling}

Given the number of measurements to be made in each occupational category within each company, workers were randomly selected from payroll rosters. Several additional workers were chosen to replace workers who could not be located or were absent on the day of measurement.

Workers and management personnel conducted the exposure survey in the field. Exposure meters were generally distributed to the selected workers by company mail. Workers who chose to participate in the survey wore the meter for a full shift and returned it after recording the on and off times. The meters were read by a field coordinator and the results recorded. The meters were periodically tested for correct functioning and calibration. 
Table 1. Characteristics of the time-weighted average (TWA) magnetic field exposure (in $\mu$ T) for 28 occupational categories. $\left(\mathrm{T}_{\mathrm{g}}=\right.$ geometric standard deviation of the total distribution, range $=$ range of individual measurements)

\begin{tabular}{|c|c|c|c|c|c|c|}
\hline Exposure level & $\begin{array}{c}\text { Number } \\
\text { of } \\
\text { measurements }\end{array}$ & $\begin{array}{l}\text { Arithmetic } \\
\text { mean }\end{array}$ & $\begin{array}{l}\text { Population } \\
\text { standard } \\
\text { error }\end{array}$ & $\begin{array}{l}\text { Geometric } \\
\text { mean }\end{array}$ & $\mathrm{T}_{\mathrm{g}}$ & Range \\
\hline \multicolumn{7}{|l|}{ Low } \\
\hline $\begin{array}{l}\text { Senior managers } \\
\text { Engineers } \\
\text { Field/craft/trade supervisors } \\
\text { Administrative supervisors } \\
\text { Administrative support/clerical workers } \\
\text { Sales, marketing and business workers } \\
\text { Services } \\
\text { Telecommunications technicians } \\
\text { Riggers } \\
\text { Auto and truck mechanics } \\
\text { Painters } \\
\text { Heavy vehicle operators } \\
\text { Laborers } \\
\text { Other crafts/trades workers }\end{array}$ & $\begin{array}{r}58 \\
70 \\
95 \\
59 \\
65 \\
66 \\
96 \\
35 \\
35 \\
47 \\
9 \\
69 \\
57 \\
100\end{array}$ & $\begin{array}{l}0.11 \\
0.23 \\
0.24 \\
0.16 \\
0.25 \\
0.12 \\
0.41 \\
0.35 \\
0.38 \\
0.20 \\
0.45 \\
0.23 \\
0.25 \\
0.21\end{array}$ & $\begin{array}{l}0.10 \\
0.64 \\
0.47 \\
0.19 \\
0.46 \\
0.07 \\
0.69 \\
0.55 \\
0.37 \\
0.21 \\
0.45 \\
0.27 \\
0.31 \\
0.25\end{array}$ & $\begin{array}{l}0.09 \\
0.12 \\
0.15 \\
0.11 \\
0.14 \\
0.10 \\
0.22 \\
0.21 \\
0.27 \\
0.14 \\
0.30 \\
0.15 \\
0.16 \\
0.15\end{array}$ & $\begin{array}{l}1.9 \\
2.3 \\
2.2 \\
2.0 \\
2.5 \\
1.8 \\
2.8 \\
2.7 \\
2.4 \\
2.3 \\
2.6 \\
2.3 \\
2.5 \\
2.3\end{array}$ & $\begin{array}{l}0.03-0.66 \\
0.03-5.32 \\
0.04-4.28 \\
0.03-1.26 \\
0.02-3.37 \\
0.03-0.37 \\
0.01-4.10 \\
0.01-3.26 \\
0.04-1.56 \\
0.03-0.94 \\
0.09-1.30 \\
0.03-1.58 \\
0.03-1.66 \\
0.01-1.26\end{array}$ \\
\hline \multicolumn{7}{|l|}{ Medium } \\
\hline $\begin{array}{l}\text { Technical Workers } \\
\text { Mechanics (plant and substation) } \\
\text { Machinists } \\
\text { Boilermakers/steamfitters } \\
\text { Instrumentation and control technicians } \\
\text { Relay technicians } \\
\text { Power plant operators } \\
\text { Substation operators } \\
\text { Pipe coverers } \\
\text { Welders } \\
\text { Material handlers }\end{array}$ & $\begin{array}{r}175 \\
100 \\
138 \\
132 \\
150 \\
63 \\
191 \\
84 \\
12 \\
76 \\
196\end{array}$ & $\begin{array}{l}0.36 \\
0.23 \\
0.72 \\
0.41 \\
0.40 \\
1.34 \\
0.79 \\
0.80 \\
0.28 \\
0.80 \\
0.23\end{array}$ & $\begin{array}{l}0.62 \\
0.30 \\
1.95 \\
1.05 \\
1.12 \\
2.34 \\
2.34 \\
1.13 \\
0.44 \\
1.08 \\
0.74\end{array}$ & $\begin{array}{l}0.18 \\
0.15 \\
0.26 \\
0.16 \\
0.21 \\
0.59 \\
0.29 \\
0.41 \\
0.17 \\
0.40 \\
0.12\end{array}$ & $\begin{array}{l}3.0 \\
2.4 \\
3.3 \\
3.0 \\
2.6 \\
3.7 \\
3.4 \\
3.3 \\
2.6 \\
3.3 \\
2.4\end{array}$ & $\begin{array}{l}0.09-5.68 \\
0.01-2.24 \\
0.01-13.5 \\
0.04-7.74 \\
0.03-13.1 \\
0.02-14.5 \\
0.01-26.4 \\
0.01-6.87 \\
0.06-1.65 \\
0.04-6.03 \\
0.01-10.1\end{array}$ \\
\hline \multicolumn{7}{|l|}{ High } \\
\hline $\begin{array}{l}\text { Electricians } \\
\text { Linemen } \\
\text { Cable splicers }\end{array}$ & $\begin{array}{l}264 \\
251 \\
149\end{array}$ & $\begin{array}{l}1.11 \\
0.65 \\
1.50\end{array}$ & $\begin{array}{l}2.18 \\
1.59 \\
3.12\end{array}$ & $\begin{array}{l}0.45 \\
0.23 \\
0.40\end{array}$ & $\begin{array}{l}3.8 \\
3.9 \\
4.8\end{array}$ & $\begin{array}{l}0.01-23.2 \\
0.01-20.8 \\
0.01-15.6\end{array}$ \\
\hline
\end{tabular}

When a meter or reader failed the calibration test, all measurements obtained with that instrument since its last successful test were excluded. The data were checked for missing or out-of-range values, logical inconsistency, and data entry errors. In addition, the correct assignment of the sampled jobs to occupational categories was checked with the aid, in part, of information collected during walk-through surveys in the companies.

\section{Statistical analysis}

After erroneous measurement data were excluded, descriptive statistics were generated with the SAS system software PC version 6.04 (SAS Institute, Cary, NC, United States). Further statistical analyses were done to obtain measures of "average" exposure and exposure variance for groups of workers. With the assumption of a random-effects analysis of variance (ANOVA) model, the within-worker variance component $\left({ }_{W W} S_{Y}^{2}\right)$ and between-worker variance component $\left({ }_{\mathrm{BW}} \mathrm{S}_{\mathrm{Y}}^{2}\right)$ were estimated by applying Proc Nested for each occupational category with repeated measurements (23). The fit of the random-effects ANOVA model was graphically judged by utilizing recently developed statis- tical procedures with the help of an SAS-Graph program (24).

The effect of different grouping strategies was assessed by applying a two-way, nested, random-effects ANOVA model (16). The goal of this procedure was to arrive at the most efficient grouping for the subsequent estimation of cumulative magnetic field exposure to be used in an exposure-response analysis of mortality data. The ratio $(\varepsilon)$ of the between-group $\left({ }_{B} S_{Y}^{2}\right)$ and the sum of the within-group and between-group variance components $\left({ }_{B G} S_{Y}^{2}+{ }_{W G} S_{Y}^{2}\right)$ was used as a measure of resolution in exposure level. This ratio had a range of 0 to 1 , the value of 1 indicating the most homogeneous possible grouping in which each worker comprised a unique group. The precision $(\pi)$ of the average exposure level for each of the groups was estimated from the median of the reciprocal of the standard error of the average exposure of each group.

Different groupings based on estimated exposure level, occupational category, company, and possible combinations of these variables were compared, as was a grouping based on the actual measured level in each of the occupational categories of the five companies. The latter was based on the distribution of the arithmetic 
mean exposure of each of the occupational categories measured successfully in each company $(\mathrm{N}=120)$. The $25,50,75$, and 87.5 percentiles were chosen as arbitrary cut-off points for the five groups.

\section{Results}

\section{Measurements}

The exposure survey was conducted between November 1990 and December 1992. Most of the measurements were done during the last 11 months of the period, with approximately 300 AMEX-3D meters in use at the end of the survey. Of the 4094 measurement attempts on eligible workers, $446(11 \%)$ did not produce usable data due to the absence of the worker, $121(3 \%)$ of the workers refused, $346(8 \%)$ were omitted due to procedural errors, and $10(0.2 \%)$ measurements were lost because of total instrument failure. Another 286 (7\%) measurements were unusable due to failure to meet the calibration criteria. An additional $43(1 \%)$ measurements were excluded from the analyses due to the fact that the measurements lasted less than $4 \mathrm{~h}$ or more than $12 \mathrm{~h}$. This left 2842 measurements in the analysis. Incorrectly coded jobs had to be recoded within the data base in 66 cases $(2 \%)$. The 662 repeated measurements were performed, on the average, $120 \mathrm{~d}$ after the initial measurement (range $1-649 \mathrm{~d}$ ).

Magnetic field exposure by estimated exposure level and occupational category

The three estimated exposure levels resulted in substantially different arithmetic mean exposures of 1.03, 0.54, and $0.24 \mu \mathrm{T}$ for the presumed high-, medium-, and low- exposure, respectively (table 2). The ranges of the arithmetic mean TWA exposures for the five companies within the high, medium, and low groups was $0.67-1.61$, $0.44-0.61$, and $0.21-0.28$, respectively (data not shown in table 2). Although the arithmetic mean exposures for these three levels of exposure were significantly different, it can be seen from table 1 that some occupational categories had exposures lower or higher than expected according to the means of the groups. In the high-exposure group the category linemen had an arithmetic mean exposure of $0.65 \mu \mathrm{T}$, half the level measured for electricians and cable splicers, who had levels of 1.11 and $1.50 \mu \mathrm{T}$, respectively. The arithmetic means for material handlers and plant and substation mechanics were also lower than those of the others in the medium-exposure group, at only $0.23 \mu \mathrm{T}$. Relay technicians appeared to have higher exposures than the others in the medium-exposure group with an arithmetic mean of $1.34 \mu \mathrm{T}$. The exposure of telecommunication technicians, riggers, service workers, and painters was also somewhat higher than that of the others in the low-exposure group, with the arithmetic mean of $0.35,0.38,0.41$, and $0.45 \mu \mathrm{T}$, respectively.

When the exposure levels for each occupational category in each of the five companies (120 groups in total) were considered, the deviations from expected levels became more apparent. For example, for the five company-specific groups of linemen, the arithmetic mean exposures were $0.94,1.03,0.69,0.57$, and $0.38 \mu \mathrm{T}$. The between-company variation for cable splicers was even more striking with $0.39 \mu \mathrm{T}$ for company $\mathrm{E}$ and 1.61 and 1.65 for companies $\mathrm{C}$ and $\mathrm{B}$, respectively (cable splicers were not present at companies $\mathrm{A}$ and $\mathrm{D})$.

The mean exposure by company was highest for the two more urban companies, although the overall differences among the companies were less than the differences between the occupational categories (table 3).

Table 2. Characteristics of the time-weighted average (TWA) magnetic field exposure (in $\mu$ ) for three estimated exposure levels. ${ }_{(} S_{g}=$ geometric standard deviation of the total distribution, range $=$ range of individual measurements $)$

\begin{tabular}{lccccc}
\hline Exposure level & $\begin{array}{c}\text { Number of } \\
\text { measurements }\end{array}$ & $\begin{array}{c}\text { Arithmetic } \\
\text { mean }\end{array}$ & $\begin{array}{c}\text { Population } \\
\text { standard error }\end{array}$ & $\begin{array}{c}\text { Geometric } \\
\text { mean }\end{array}$ & $T_{9} S_{g}$ \\
\hline Low & 861 & 0.24 & 0.42 & 0.15 & 2.4 \\
Medium & 1317 & 0.54 & 1.44 & 0.22 & $0.01-5.32$ \\
High & 664 & 1.03 & 2.27 & 0.34 & $0.01-26.4$ \\
\hline
\end{tabular}

Table 3. Characteristics of the time-weighted average (TWA) magnetic field exposure (in $\mu$ ) for the five electric utility companies. ${ }_{(} S_{g}=$ geometric standard deviation of the total distribution, range = range of individual measurements)

\begin{tabular}{|c|c|c|c|c|c|c|c|c|}
\hline Company & Size & Type & $\begin{array}{c}\text { Number } \\
\text { of } \\
\text { measurements }\end{array}$ & $\begin{array}{c}\text { Arithetic } \\
\text { mean }\end{array}$ & $\begin{array}{l}\text { Population } \\
\text { standard } \\
\text { error }\end{array}$ & $\begin{array}{c}\text { Geometric } \\
\text { mean }\end{array}$ & ${ }_{\gamma} S_{g}$ & Range \\
\hline A & Small & Less urban & 272 & 0.41 & 0.59 & 0.21 & 2.9 & $0.03-4.28$ \\
\hline$B$ & Medium & More urban & 322 & 0.66 & 1.82 & 0.26 & 3.1 & $0.01-23.3$ \\
\hline $\mathrm{C}$ & Large & More urban & 883 & 0.69 & 1.90 & 0.23 & 3.6 & $0.01-20.8$ \\
\hline D & Large & Rural & 931 & 0.50 & 1.16 & 0.19 & 3.4 & $0.01-13.1$ \\
\hline$E$ & Medium & Less urban & 434 & 0.47 & 1.43 & 0.22 & 2.9 & $0.01-26.4$ \\
\hline
\end{tabular}


Within- and between-worker components of variance for occupational categories

Generally, the TWA magnetic field exposure varied more on a day-to-day basis for an individual worker than between workers. However, for technical workers, relay technicians, and material handlers the opposite pattern was observed (table 4). The largest differences between the individual average of magnetic field exposures occurred for technical workers, relay technicians, power plant operators, electricians, and cable splicers $\left(_{B W} \hat{R}_{0.95}>\right.$ 20). Only the occupational categories mechanics and welders could be considered uniformly exposed groups, based on ${ }_{\mathrm{BW}} \hat{R}_{0.95} \leq 2$ as defined by Rappaport (15).

\section{Comparison of grouping schemes}

The results of analyses to compare the efficiency of four a priori schemes (estimated exposure level, occupational category, company, and occupational category and company combined) and one a posteriori scheme (measured exposure level) for grouping workers are shown in table 5 . The groupings by occupational category, occupational category plus company, and the a posteriori group- ing (with the 25,50,75, and 87.5 percentiles of the distribution of average exposures (arithmetic means) of the 120 occupational category plus company groups as cut-off points) showed the greatest contrast in exposure levels between the created groups, as indicated by $\varepsilon$ and ${ }_{B \mathrm{~B}} \hat{\mathrm{R}}_{0.95}$. The estimated exposure gave the highest precision $(\pi=27.8)$, but relatively poor resolution between groups ${ }_{B G} \hat{R}_{0.95}=4.5, \varepsilon=0.29$ ). The grouping based on measured exposure yielded similar precision $(\pi=25.5)$ but far better resolution between the groups ${ }_{B \mathrm{BG}} \hat{\mathrm{R}}_{0.95}=$ $8.6, \varepsilon=0.59)$ and was selected as the basis for the jobexposure matrix for exposure to magnetic fields.

\section{Elaborating the job-exposure matrix for magnetic fields}

Table 6 gives descriptive statistics for the groups after the 120 occupational category-company combinations were aggregated into five exposure groups. The confidence intervals were based on both the within- and between-worker components of variance, which were estimated for each of the five exposure groups. The very small number of repeated measurements in the first two

Table 4. Within- and between-worker components of variance in several occupational categories. ( ${ }_{\mathrm{B} w} \mathrm{~S}_{\mathrm{g}}=$ geometric standard deviation for the between-worker distribution, ${ }_{8 w} \hat{R}_{0.95}=$ ratio of 97.5 th and 2.5 th percentiles of the between-worker distribution, ${ }_{w w} \mathrm{~S}_{\mathrm{g}}=$ geometric standard deviation for the within-worker distribution)

\begin{tabular}{|c|c|c|c|c|c|c|}
\hline Occupational category & $\begin{array}{c}\text { Number } \\
\text { of measurements }\end{array}$ & $\begin{array}{l}\text { Number } \\
\text { of workers }\end{array}$ & $\begin{array}{l}\text { Arithmetic } \\
\text { mean }\end{array}$ & ${ }_{\mathrm{B} W} \mathrm{~S}_{\mathrm{g}}$ & ${ }_{B W} \hat{R}_{0.95}$ & ${ }_{w w} \mathrm{~S}_{9}$ \\
\hline Other crafts/trades workers & 100 & 74 & 0.21 & 1.40 & 3.76 & 2.13 \\
\hline Technical workers & 175 & 130 & 0.36 & 2.27 & 24.9 & 2.06 \\
\hline Mechanics (plant and substation) & 100 & 86 & 0.23 & 1.19 & 1.96 & 2.37 \\
\hline Machinists & 138 & 96 & 0.72 & 1.69 & 7.86 & 2.90 \\
\hline Boilermakers/steamfitters & 132 & 88 & 0.41 & 1.46 & 4.39 & 2.82 \\
\hline Instrumentation and control technicians & 150 & 102 & 0.40 & 1.59 & 6.17 & 2.33 \\
\hline Relay technicians & 63 & 43 & 1.34 & 2.66 & 46.0 & 2.40 \\
\hline Power plant operators & 191 & 148 & 0.79 & 2.23 & 23.5 & 2.52 \\
\hline Substation operators & 84 & 55 & 0.80 & 1.90 & 12.4 & 2.73 \\
\hline Welders & 76 & 58 & 0.80 & 1.00 & 1.00 & 3.30 \\
\hline Material handlers & 196 & 121 & 0.23 & 1.90 & 12.3 & 1.82 \\
\hline Electricians & 264 & 167 & 1.11 & 2.27 & 25.1 & 2.87 \\
\hline Linemen & 251 & 161 & 0.65 & 2.04 & 16.3 & 3.20 \\
\hline Cable splicers & 149 & 97 & 1.50 & 2.27 & 24.7 & 3.81 \\
\hline
\end{tabular}

Table 5. Grouping efficiency based on all measurements $(\mathrm{N}=2842) .\left({ }_{\mathrm{BG}} \mathrm{S}_{Y}^{2}=\right.$ variance of the between-group distribution of logtransformed exposures, ${ }_{B G} \hat{R}_{0.95}=$ ratio of 97.5 th and 2.5 th percentiles of the between-group distribution, ${ }_{W G} S_{Y}^{2}=$ variance of the within-group distribution of log-transformed exposures, $\varepsilon=$ ratio of ${ }_{B G} S_{Y}^{2}$ and sum of ${ }_{B G} S_{Y}^{2}$ and ${ }_{W G} S_{Y}^{2}$, wm $S_{Y}^{2}=$ variance of the withinworker distribution of log-transformed exposures, $\pi=$ median precision)

\begin{tabular}{|c|c|c|c|c|c|c|c|c|}
\hline Grouping & $\begin{array}{l}\text { Number } \\
\text { of } \\
\text { groups }\end{array}$ & $\begin{array}{c}\text { Number } \\
\text { of } \\
\text { workers }\end{array}$ & ${ }_{B G} S_{Y}^{2}$ & ${ }_{B G} \hat{R}_{0.95}$ & ${ }_{W G} S_{Y}^{2}$ & $\varepsilon$ & ${ }_{W} S_{Y}^{2}$ & $\pi$ \\
\hline Estimated exposure & 3 & 2177 & 0.1452 & 4.45 & 0.3606 & 0.29 & 0.9843 & 27.8 \\
\hline Occupational category & 28 & 2180 & 0.2245 & 6.41 & 0.2360 & 0.49 & 0.9883 & 9.9 \\
\hline Company & 5 & 2170 & 0.0109 & 1.51 & 0.4407 & 0.02 & 0.9888 & 19.2 \\
\hline $\begin{array}{l}\text { Occupational } \\
\text { category-company }\end{array}$ & 120 & 2180 & 0.2529 & 7.18 & 0.2003 & 0.56 & 0.9883 & 5.0 \\
\hline Measured exposure & 5 & 2180 & 0.3017 & 8.61 & 0.2124 & 0.59 & 0.9883 & 25.5 \\
\hline
\end{tabular}


Table 6. Descriptive statistics for the grouping based on measured exposure (in $\mu \top)$. ${ }_{T} \mathrm{~S}_{\mathrm{g}}=$ geometric standard deviation of the total distribution, ${ }_{B w} \mathrm{~S}_{\mathrm{g}}=$ geometric standard deviation for the between-worker distribution, ${ }_{\mathrm{Bw}} \hat{\mathrm{R}}_{0.95}=$ ratio of 97.5 th and 2.5 th percentiles of the between-worker distribution, $w_{w} S_{g}=$ geometric standard deviation for the within-worker distribution, range $=$ range of arithmetic means of occupational category-company combinations)

\begin{tabular}{|c|c|c|c|c|c|c|c|c|c|c|c|}
\hline Group & $\begin{array}{l}\text { Number } \\
\text { of } \\
\text { measure- } \\
\text { ments }\end{array}$ & $\begin{array}{l}\text { Number } \\
\text { of } \\
\text { workers }\end{array}$ & $\begin{array}{c}\text { Arithmetic } \\
\text { mean }\end{array}$ & $\begin{array}{c}95 \% \\
\text { confidence } \\
\text { interval of } \\
\text { arithmetic } \\
\text { mean }\end{array}$ & $\begin{array}{c}\text { Geometric } \\
\text { mean }\end{array}$ & $\begin{array}{l}95 \% \text { contidence } \\
\text { interval of } \\
\text { geometric mean }\end{array}$ & $\mathrm{T}_{\mathrm{g}}$ & ${ }_{\mathrm{B} w} \mathrm{~S}_{\mathrm{g}}$ & ${ }_{\mathrm{B}} \hat{\mathrm{R}}_{0.95}$ & $w w S_{g}$ & Range \\
\hline 1 & 347 & 331 & 0.12 & $0.11-0.13$ & 0.10 & $0.09-0.11$ & 1.8 & 1.0 & 1.00 & 2.1 & $0.05-0.15$ \\
\hline 2 & 511 & 441 & 0.21 & $0.19-0.23$ & 0.15 & $0.14-0.16$ & 2.3 & 1.6 & 6.28 & 2.0 & $0.15-0.30$ \\
\hline 3 & 821 & 621 & 0.39 & $0.33-0.45$ & 0.19 & $0.18-0.20$ & 2.8 & 1.8 & 11,0 & 2.3 & $0.30-0.48$ \\
\hline 4 & 529 & 363 & 0.62 & $0.50-0.74$ & 0.25 & $0.23-0.28$ & 3.5 & 1.9 & 11.8 & 3.0 & $0.48-0.80$ \\
\hline 5 & 634 & 424 & 1.27 & $1.07-1.48$ & 0.46 & $0.41-0.51$ & 4.0 & 2.2 & 21.3 & 3.1 & $0.80-2.00$ \\
\hline
\end{tabular}

groups (groups 1 and 2) resulted in very unstable estimates of the within- and between-worker components of variance. From this table it follows that both the between-worker and the within-worker component tended to increase with increasing level of exposure. However, in all cases, the within-worker component exceeded the between-worker component.

Given that the difference in average exposure level between the highest and lowest exposed groups was about a factor of 10 (see also the estimated ${ }_{\mathrm{BG}} \hat{\mathrm{R}}_{0.95}$ of $8.61 \mathrm{in}$ table 5), it is also obvious that overlap in exposure level due to the large within-group (between-worker within a group) variance will still be present; the three highest exposed groups had especially large ${ }_{B W} \hat{R}_{0.95}$ of 11,12 , and 21.

No exposure data were obtained for 14 occupational category-company combinations. Eight groups with few workers were not selected in the random sample, and another six were historical groups no longer present. Average exposure levels for the 14 groups were imputed according to a linear model with occupational categories and company as independent factors and the untransformed TWA magnetic field exposure as the dependent variable. Due to the large day-to-day variability, this model explained only $7 \%$ of the total exposure variance. According to the estimated exposure, these groups were placed in one of the five exposure categories. The 120 sampled occupational category-company combinations were placed in one of the five exposure categories according to their actual measured level of magnetic field exposure (arithmetic mean). Six occupational categorycompany combinations had never been present.

\section{Discussion}

\section{Measurement strategy}

The measurement strategy has been extensively discussed by Loomis et al (18). In this report, we have restricted the discussion to the number of repeated measurements and the applied weights for the number of measurements for each assumed level of exposure.

Unfortunately, the number of repeated measurements was much smaller than planned. Although the failure rate was similar for first and second measurement attempts on the same worker, the $30 \%$ unusable measurements for both first and second measurements restricted the planned number of repeats. In addition the end of the survey period precluded attempts to obtain second measurements for many workers.

As expected, the variability of magnetic field exposure increased with the assumed level of exposure. However, the standard error increased by factors of 3.4 and 5.4 for the two higher levels when compared with the lowest level. Therefore, a weighting of 1,12 , and 29 instead of the applied 1,3, and 5 for the relative number of samples to be collected within the three assumed levels would have been required to attain the same precision of average exposure.

\section{Comparison with other studies}

Comparable patterns are seen when the average magnetic fields measured for the preassigned exposure levels of $0.24,0.51$, and $1.03 \mu \mathrm{T}$ are compared with previously published results. Flynn et al (8) used an a priori ranking of magnetic field exposure into three levels for 134 employees in one utility company and showed average exposure levels of $0.10,0.61$, and $1.51 \mu \mathrm{T}$ for the ranks low, medium, and high, respectively, after validation with actual measurements performed with the EMDEX meter. The fact that the difference between the highest and lowest level assigned was about three times as high in the study of Flynn et al (1.51 over $0.10 \mu \mathrm{T}$ compared with 1.03 over $0.24 \mu \mathrm{T}$ ) may be partly related to the fact that only one company was involved. In addition, individual jobs rather than occupational categories were rated by Flynn et al. Nevertheless, the differences are relatively small in $a b-$ solute terms. 
Lindh \& Andersson (24) ranked occupations into low, medium, and high exposure groups according to measured fields. The resulting average exposure levels were $0.06,0.28$, and $1.47 \mu \mathrm{T}$. Their results are less comparable, however, because they applied a procedure of disregarding extreme values and used a different exposure meter (25).

Our levels for utility workers were notably lower than the levels reported by Deadman et al (7) and Bowman et al (9). The contrast with the latter study may be explained by the investigators having made nonrandom spot measurements, leading to upwardly biased exposure levels. The discrepant geometric mean reported for magnetic fields by Deadman et al are less readily explained, because these researchers also performed repeated fullshift personal monitoring. It is unlikely that the five- to eight-fold difference in exposure seen for such jobs as electricians, cable splicers, linemen, power plant mechanics, and power plant operators can be attributed to differences in work practices and power production and delivery methods between the United States and Canada or to differences due to the time span of five years that has passed since the study by Deadman et al. The more likely reasons are differences between the meters and measurement strategies (random selection of workers and days of measurement in our study). To our knowledge, no formal comparison of the meter described by Deadman et al (7) and the AMEX-3D has been carried out, as was done for the AMEX 3-D and the EMDEX-100 meter (21).

This study corroborated the pattern in the variability of magnetic field exposure reported by Deadman et al (7). In their study, the day-to-day component of variance was also greater than the between-worker component of variance for workers exposed at and above background levels, as well as for the subgroup of 10 linemen. The between-worker geometric standard deviation for linemen in our study compared reasonably well with that reported by Deadman et al (2.31 versus 2.05$)$. The dayto-day component of variance was larger in our study (3.20 versus 2.34 ), probably due to the relative short measurement period in the Deadman et al study (all measurements having been performed within one week).

The resolution in magnetic field exposure levels for occupational category $(\varepsilon=0.49)$ is at the higher end of the distribution for similar general grouping variables for chemical exposures. Kromhout (26) reported resolutions ranging from 0.00 to 0.59 for nine chemical exposures in six industry-wide exposure surveys. The small differences between companies within the electric power industry ( $\varepsilon=0.02$ ) is at the very low end of the distribution for chemical exposures $(\varepsilon=0.00-0.86)$. The mix of jobs and tasks, their actual content, and the way power is produced and delivered apparently does not lead to distinct differences in average exposure levels between com- panies. The combination of occupational category and company therefore gives resolution in exposure level $(\varepsilon=0.56)$ near the middle of the range for chemical exposures $(\varepsilon=0.30-0.84)$.

\section{Population-specific job-exposure matrices}

The population-specific job-exposure matrix developed in this study takes into account the differences in exposure level within occupational categories between companies. Unfortunately 14 cells of the matrix were not measured and had to be estimated from a statistical model that explained only $7 \%$ of the total variability. However, given the very large portion of day-to-day variability ( $70 \%$ ) only $30 \%$ could have been explained, at the most, by the two factors occupational category and company.

The job-exposure matrix features only one exposure measure (TWA magnetic field), but several other potential measures, like the geometric mean, median, 90th percentile, and higher cut-off scores correlate reasonably well with the TWA $(27,28)$. Using the TWA alone did not sacrifice statistical power in our study of electrical utility workers (20). However, the correlation of the TWA magnetic fields with lower cut-off scores, electric fields, and high-frequency transients $(27,28)$ were generally weak and may need to be assessed separately.

No measurements of historical magnetic field exposures had been taken and no precise historical data on power generation, power line loads, work patterns, work hours, or the like existed. Therefore, it was decided not to estimate past exposures by adjusting present quantitative exposure levels. General multipliers could not be derived from available information, and the noise inherent in these multipliers may not have generated more reliable estimates for the past. Some evidence was available, however, that the relative ranking of occupational categories, if not the absolute level of exposure, had been stable over the four decades studied (1950-1988). Bowman et al (13) reported few differences between current and historical (past) estimates of exposure based on adjustments for different time-activity profiles.

\section{Concluding remarks}

In conclusion, the measurement strategy used in this study resulted in quantitative estimates of present exposure to $60-\mathrm{Hz}$ magnetic fields for 28 occupational categories in five companies. The population-specific job-exposure matrix will enable cumulative magnetic field exposure to be estimated. Whether the optimal (given the limitations of the survey) grouping of magnetic field exposure will yield groups of workers with distinctly different levels of cumulative exposure will depend on the distribution of person-years spent in the different occupational categories. However, classifying exposure 
without any formal consideration of exposure variability might have led to a study with inadequate statistical power to detect relations between magnetic field exposure and cancer.

Available personal meters should be reliably calibrated and extensively compared for monitoring magnetic field exposure to provide a better understanding of observed differences between exposure surveys. This information will also facilitate the setting and control of future occupational exposure limits if needed.

\section{Acknowledgments}

This study was supported by the Electric Power Research Institute (contract RP 2964-5).

\section{References}

1. Milham S. Mortality from lenkemia in workers exposed to electrical and magnetic fields [letter]. N Engl J Med 1982; 307:249.

2. Wright WE, Peters JM, Mack TM. Leukaemia in workers exposed to electrical and magnetic fields [letter]. Lancet $1982 ; 2: 1160-1$.

3. Coleman M, Bell J, Skeet R. Leukaemia incidence in electrical workers [letter]. Lancet 1983;1:982 - 3 .

4. McDowall ME. Leukaemia mortality in electrical workers in England and Wales [letter]. Lancet 1983;1:246.

5. Thériault GP. Health effects of electromagnetic radiation on workers: epidemiologic studies. In: Bierbaum PJ, Peters J, editors. Proceedings of the scientific workshop on the health effects of electric and magnetic fields on workers. Cincinnati, $\mathrm{OH}$ : National Institute for Occupational Safety and Health, 1991:91-124. DHHS NIOSH publication no 91-111.

6. Kromhout $\mathrm{H}$. Incidence of leukaemia and brain tumours in some "electrical occupations" [letter]. Br J Ind Med 1992; 49:375.

7. Deadman JE, Camus M, Armstrong BG, Héroux P, Cyr D, Plante $\mathrm{M}$, et al. Occupational and residential $60-\mathrm{Hz}$ electromagnetic fields and high frequency electric transients: exposure assessment using a new dosimeter. Am Ind Hyg Assoc J 1988:49:409-19.

8. Flynn MR, West S, Kaune WT, Savitz DA, Chen C-C, Loomis DP. Validation of expert judgement in assessing exposure to magnetic fields in the utility industry. Appl Occup Environ Hyg 1991;6:141-5.

9. Bowman JD, Garabrant DH, Sobel E, Peters J. Exposures to extremely low frequency (ELF) electromagnetic fields in occupations with elevated leukemia rates. Appl Ind Hyg 1988; 3:189-94.

10. Sahl JD, Kelsh MA, Greenland S. Cohort and nested casecontrol studies of hematopoitic cancers and brain cancer among electric utility workers. Epidemiology 1993;4:104 14.

11. Matanoski GM, Elliott EA, Breysse PN, Lynberg MC. Leuke- mia in telephone linemen. Am J Epidemiol 1993;137:60919.

12. Bracken TD. The EMDEX project: technology transfer and occupational measurements, vol $1-3$ (interim report). Palo Alto, CA: Electric Power Research Institute, 1990. EPRI EN7048.

13. Bowman JD, Sobel E, London SJ, Thomas DC, Gabarant DH, Pearce N, et al. Electric and magnetic field exposure, chemical exposure, and leukemia risk in "electrical" occupations. Palo Alto, CA: Electric Power Research Institute 1992. EPRI TR101723.

14. Oldham PD, Roach SA. A sampling procedure for measuring industrial dust exposure. Br I Ind Med 1952;9:112-9.

15. Rappaport SM. Assessment of long-term exposures to toxic substances in air. Ann Occup Hyg 1991;35:61-121.

16. Kromhout H, Heederik D. Occupational epidemiology in the rubber industry: implications of exposure variability. Am J Ind Med. In press.

17. Kromhout H, Loomis DP, Savitz DA, Mihlan GJ, Bracken TD, Senior RS. Patterns of electric and magnetic field exposure in the utility industry. In: National Institute for Occupational Safety and Health (NIOSH). Proceedings of the 9th international symposium on epidemiology in occupational health, Cincinnati September, 1992. Cincinnati, OH: NIOSH 1992:325-9. DHHS (NIOSH) publication no 94-112.

18. Loomis DP, Kromhout H, Peipins LA, Kleckner RC, Iriye R, Savitz DA. Sampling design and field methods of a large, randomized, multi-site survey of occupational magnetic field exposure. Appl Occup Environ Hyg 1994;9:49—52.

19. Loomis DP, Peipins LA, Browning SR, Howard RL, Kromhout $\mathrm{H}$, Savitz DA. Organization and classification of work history data in industry-wide studies: an application to the electric power industry. Am J Ind Med 1994;26:413-25.

20. Savitz DA, Loomis DP. Magnetic field exposure in relation to leukemia and brain cancer mortality among electric utility workers. Am J Epidemiol 1995;14:123 - 34.

21. Kaune WT, Niple JC, Liu MJ, Silva J. Small integrating meter for long-term magnetic field exposure assessment. Bioelectromagnetics 1992;13:413-27.

22. Héroux P. A dosimeter for assessment of exposures to ELF fields. Bioelectromagnetics 1991;12:241-57.

23. Kromhout H, Symanski E, Rappaport SM. A comprehensive evaluation of within- and between-worker components of occupational exposure to chemical agents. Ann Occup Hyg 1993; $37: 253-70$.

24. Lindh TO, Andersson L-I. Exposure of workers in the electric power industry to $50-\mathrm{Hz}$ electric and magnetic fields. Solna: Arbetsmiljöinstitutet, 1992.

25. Lindh TO, Andersson L-I. Power frequency electric and magnetic fields: a personal exposimeter. Stockholm: Arbetarskyddsverket, 1989. Arbete och hälsa 1989:8.

26. Kromhout $H$. Industry-wide exposure variability. Presented at the first international conference of the International Occupational Hygiene Association, Brussels, December 1992.

27. Armstrong BG, Deadman JE, Thériault, G. Comparison of indices of ambient exposure to 60 -Hertz electric and magnetic fields. Bioelectromagnetics 1990;11:337-47.

28. Savitz DA, Ohya T, Loomis DP, Senior RS, Bracken TD, Howard RL. Correlations among indices of electric and magnetic field exposure in electric utility workers. Bioelectromagnetics 1994;15:193-204.

Received for publication: 14 February 1994 